\title{
CONSTRUINDO BRINQUEDOS NA EDUCAÇÃO INFANTIL: UMA EXPERIÊNCIA COM A TEORIA ECOLÓGICA DO DESENVOLVIMENTO HUMANO
}

Tatiane Gibertoni Sai

Ademir De Marco

\section{Resumo}

Este estudo investigou as relações interpessoais que as crianças estabelecem ao interagir com o brinquedo construído por elas em dois contextos, durante a construção e o desenvolvimento de atividades com o brinquedo na sala de aula e na própria casa da criança. Para isto contou com 17 participantes de ambos os sexos, com idade entre 4 e 5 anos, da instituição Prodecad/Unicamp. Foram desenvolvidas seis aulas de construção de brinquedos, sendo três de construção e três de atividades motoras com os brinquedos. Este estudo foi fundamentado na Teoria Ecológica do Desenvolvimento Humano (TEDH), de Bronfenbrenner (1996), e constitui estratégia adequada para a avaliação das relações interpessoais estabelecidas entre as crianças no ambiente escolar e com os familiares no espaço domiciliar.

\section{Palavras-Chaves}

Criança; Educação infantil; Brinquedo; Teoria ecológica.

\section{CONSTRUCTING TOYS IN THE INFANTILE EDUCATION: AN EXPERIENCE WITH THE ECOLOGICAL THEORY OF THE HUMAN DEVELOPMENT}

Tatiane Gibertoni Sai

Ademir De Marco

\begin{abstract}
This study investigated the interpersonal relations that the children establish when interacting with the toy constructed by them in two contexts, during the construction and the development of the activities with the toy in the classroom and it the proper house of the child. For this, it counted on 17 participants of both sex, with age between 4 and 5 years, of the Prodecad/Unicamp institution. Six toy construction lessons, being three of construction and three of motor activities with the toys, have been developed. This study was based on Human Development Ecological Theory (TEDH), by Bronfenbrenner(1996), and is appropriate for the evaluation of interpersonal relations established among children in the pertaining to school environment and with the relatives in the domiciliary environment.
\end{abstract}

\section{Key-Words}

Child; Education for childrens; Toy; Ecological theory. 


\section{INTRODUÇÃO}

Entender como a criança se desenvolve quando produz cultura é de suma importância e nos remete a algumas hipóteses sobre como esta criança vai se comportar realizando este tipo de atividade, qual o significado que isto representará a ela, como este momento refletirá em outros ambientes e no estabelecimento de relações interpessoais, enfim, será que o ato de construir brinquedos é um meio facilitador para o desenvolvimento? Foi a partir destes questionamentos que este estudo se estruturou.

Mas que tipo de possibilidades os brinquedos da atualidade oferecem às crianças? Sendo que estes já estão prontos e se movimentam automaticamente, limitando a participação da criança na brincadeira em apenas um acionar de botões e com restrições da criatividade. Refletindo sobre este panorama atual, este estudo se contrapõe a esta lógica, desenvolvendo brinquedos construídos pelas próprias crianças e analisando como elas se relacionam com as demais durante esta prática, além de procurar entender se este brinquedo construído exerce influência sobre um outro ambiente.

O compartilhar da visão de criança como um ser ativo que influencia e é influenciado pelo ambiente no qual está inserido, nos fez buscar uma teoria que contemplasse esta vertente. A Teoria Ecológica do Desenvolvimento Humano -TEDH- postulada por Bronfenbrenner (1996), concebe o desenvolvimento como "a concepção desenvolvente da pessoa do meio ambiente ecológico, e sua relação com ele, e também como a crescente capacidade da pessoa de descobrir, sustentar ou alterar suas propriedades" (BRONFENBRENNER, 1996, p. 10).

A teoria base deste estudo compreende uma nova maneira de analisar e discutir o desenvolvimento, com uma visão referente ao contexto em que a pessoa está inserida. A TEDH fundada sob dois pressupostos; o primeiro referente aos atributos da pessoa, entendidos em uma perspectiva ecológica, o segundo referente aos parâmetros do contexto, compreendidos em uma abordagem desenvolvimentista, constituem o modelo Bioecológico, referenciando as quatro variáveis: contexto/pessoa/processo/tempo. (KREBS, 2003; 2005).

Tendo como exemplo bonecas russas, Bronfenbrenner concebe o ambiente ecológico como estruturas sobrepostas. No primeiro nível, o mais interno, encontra-se o ambiente imediato da pessoa em desenvolvimento, o microssistema. Em segundo nível está o ambiente que faz ligação com o imediato, o mesossistema. No terceiro nível, encontra-se o ambiente ecológico no qual a pessoa em desenvolvimento não participa efetivamente, mas os eventos ocorridos neste a afetam diretamente, este é o 
exossistema. Por último, englobando os demais sistemas, encontra-se o macrossistema, que diz respeito às influencias da cultura, subcultura, sociedade, de uma forma mais ampla, sobre o desenvolvimento da pessoa. (BRONFENBRENNER, 1996).

O complexo pessoa/processo/contexto/tempo, integra as características biológicas e sociais da pessoa em desenvolvimento; as mudanças que ocorreram ao longo da vida, que são os processos; as características dos ambientes, o contexto; e os eventos sócio-culturais ou biológicos que influenciaram o desenvolvimento, o tempo. (KREBS, 2001a).

\section{OBJETIVO}

Analisar as relações inter-pessoais que são estabelecidas pelas crianças com a construção e interação com os brinquedos em dois contextos, durante as aulas de construção de brinquedos e no ambiente doméstico da criança.

\section{METODOLOGIA}

Caracterizado como um estudo de caso, de natureza qualitativa, esta pesquisa define-se também como um estudo ecológico, pois se fundamenta nos pressupostos da Teoria Ecológica do Desenvolvimento Humano, postulada por Bronfenbrenner (1996). Este estudo tem a aprovação do Comitê de Ética em Pesquisa da FCM/Unicamp/SP, sob o parecer nº 619/2006.

Desenvolvida com dezessete crianças, de ambos os sexos, com idade entre quatro e cinco anos, da instituição Prodecad/Unicamp, no município de Campinas/SP, para contemplar esta pesquisa foram realizadas seis aulas, sendo três de construção de brinquedos e três de atividades com o brinquedo, em uma aula as crianças construíam o brinquedo e na aula seguinte desenvolviam atividades motoras de exploração com estes. Após o término desta aula, as crianças levavam o brinquedo para a sua residência, juntamente com um questionário para os pais, visando obter informações acerca do que a criança fez com o brinquedo no âmbito de sua casa.

Os brinquedos construídos foram: bola maluca, garrafa colorida e brinquedo livre, tendo sido disponibilizados diversos materiais considerados como sucata.

No decorrer das aulas, que tiveram duração de 50 minutos cada, em média. Foi solicitado a dois observadores (professora e auxiliar de sala), que preenchessem um diário de campo, sem que houvesse comunicação entre ambos. Foram desenvolvidos dois modelos de diário de campo, um para as aulas de 
construção e outro para as aulas de atividades com o brinquedo. Estes diários seguiram as orientações de Faria Júnior (1987), e foram embasados na Teoria Ecológica de Bronfenbrenner (1996).

Os dois modelos de diário de campo podem ser subdivididos em três partes: 1) índice, que caracteriza o ambiente, o público alvo; 2) pontos relevantes de acordo com a teoria ecológica postulada por Urie Bronfenbrenner (1996); 3) observações livres que podem ser relevantes e que não são contempladas nos dois itens anteriores.

O questionário que era enviado aos pais, elaborado conforme as instruções de Fachin (2001), visou investigar de que forma a criança interagiu com o brinquedo em outro microssistema.

Outro meio de avaliação foram as filmagens de duas aulas, sendo a primeira e a última de construção de brinquedos. Estas filmagens seguiram as orientações de De Marco (2006), com a utilização de quatro câmeras de uso doméstico, fixas em tripés, posicionadas uma em cada canto do ambiente. Com esta coleta, pretendiam-se analisar as relações interpessoais, as atividades e os papéis, elementos do microssistema.

\section{RESULTADOS}

Conforme os pressupostos da teoria ecológica (BRONFENBRENNER, 1996), foram analisados os atributos da pessoa (disposições, recursos e demandas), e os parâmetros do contexto (micro, meso e macrossistemas).

Considerando o ambiente "instituição Prodecad" como um microssistema, a aula de construção de brinquedos age como contexto primordial ou secundário de desenvolvimento, de acordo com Krebs (2004) deve favorecer a aquisição de habilidades e estimular a independência e a autonomia na aquisição de novos conhecimentos. A relação entre os microssistemas "instituição" e "casa da criança", consiste na formação de um mesossistema.

Portanto, foram analisados os três elementos que compõe o microssistema, as atividades, as relações interpessoais e os papéis. Quanto às atividades, Bronfenbrenner (1996) classificou-as como molar ou molecular. Investigar a molaridade da brincadeira com o brinquedo é relevante para entender se este provocou algum tipo de impacto no ambiente da casa da criança, pois Bronfenbrenner (1996) relata que as atividades molares têm variadas funções sobre o desenvolvimento, servindo como causa, contexto e conseqüência do crescimento psicológico. 
Com o brinquedo bola maluca foi registrado na filmagem, que para todas as crianças a atividade foi considerada molar, devido ao empenho e ao cumprimento do objetivo desta. No questionário para os pais, pode-se perceber o mesmo efeito, pois em todos os questionários devolvidos, constam que as crianças utilizaram o brinquedo de diversas maneiras.

O brinquedo garrafa colorida, também foi considerado como uma atividade molar para todas as crianças, pois todas completaram e envolveram-se muito na construção, porém, dos poucos questionários devolvidos (apenas oito), demonstram que as crianças pouco utilizaram o brinquedo para brincar em casa, culminando no entendimento de que este brinquedo não se apresentou como uma atividade molar no microssistema, casa. Este fato pode ter diversas raízes, uma delas relacionada com a complexidade da atividade, por ser considerada uma atividade de fácil realização pode não ter instigado na criança o potencial necessário para impactar as relações em outro ambiente.

Os escritos de Vigotski (2007) trazem uma idéia de entendimento para este fenômeno. Segundo o autor, um objeto pode ser modificado pela criança, adquirindo nova estrutura e significado, em um contexto que permite a criança modificar a ordem das coisas, isto ocorreu durante o período de aula com a garrafa plástica, ela foi transformada a ponto de tornar-se um brinquedo, porém no âmbito do mesossistema este objeto pode ter reassumido seu significado, voltado a ser apenas uma garrafa, devido ao ambiente, pois este não estava mais inserido em um contexto de fantasia.

As relações interpessoais, elemento do microssistema, ocorrem quando uma pessoa participa ou presta atenção à atividade de outra pessoa. Na aula do brinquedo bola maluca, foi identificada durante a filmagem, treze relações, sendo sete de observação e seis de participação conjunta. O brinquedo bola maluca foi mostrado para terceiros por dez crianças, sete utilizaram o brinquedo para brincar com outras crianças. Estas relações foram estabelecidas entre irmãos, primos, tios, pais e amigos, reforçando que a família, de acordo com Bronfenbrenner (1996) e Krebs (2005), é a principal fonte de influência e exemplos da criança, até que esta ingresse em uma instituição infantil, primeiro ambiente freqüentado pela criança fora do lar.

Esta atitude de brincar junto é considerada uma díada de participação conjunta, pôde-se perceber a ocorrência destas relações. De acordo com os dados dos questionários entende-se que as crianças estabeleceram mais, relações interpessoais de participação conjunta, no âmbito da casa em comparação ao ocorrido nas aulas. 
Convém lembrar que duas crianças levaram o brinquedo para um terceiro ambiente (terceiro microssistema), estabelecendo relações neste também. Estas relações de participação conjunta constituem um contexto crítico para o desenvolvimento, fomentando o crescimento psicológico. (BRONFENBRENNER,1996).

As informações contidas no diário de campo do brinquedo garrafa colorida, demonstraram manifestações de auxílio entre as crianças, conforme terminavam de construir o brinquedo, auxiliavam quem ainda o estava fazendo; este tipo de atitude representa relações de participação conjunta. Quanto ao questionário, apenas uma criança utilizou o brinquedo para brincar com alguém, e a mesma levou o brinquedo para um terceiro ambiente. Este brinquedo fomentou a formação de pouquíssimas relações interpessoais no mesossistema, por outro lado esta afirmativa não é conclusiva, pois um pequeno número de questionários foi respondido pelos pais, representando menos da metade dos alunos.

O terceiro elemento do microssistema, a representação de papel social, ocorreu apenas uma vez, na aula de construção livre, quando um menino imitou um noivo, isto se deve ao fato de que o material usado pela criança para esta encenação, já predispunha esta representação, pois a criança amarrou um pedaço de Me (usado para véu de noivas) em seu corpo e brincou de encontrar uma noiva, pedindo diversas meninas em casamento. É importante ressaltar que apesar deste material j á ter um significado social, a criança precisou de sua imaginação para transformá-lo e associá-lo a este papel, utilizando o objeto como um brinquedo.

Durante as aulas foram identificadas algumas manifestações de disposições, tanto disruptivas quanto geradoras. As disposições desenvolvimentalmente disruptivas do pólo passivo foram identificadas quando duas crianças recusaram-se a participar da atividade proposta. As disposições disruptivas do pólo ativo ocorreram com maior freqüência, em manifestações de desentendimento e de agressividade entre as crianças. Atitudes de desentendimento entre as crianças por disputa de material ou troca acidental de brinquedos também são consideradas segundo Bronfenbrenner (1996) como disposições disruptivas do pólo ativo, porém ao se reportar a faixa etária das crianças, de 4 a 5 anos, é possível entender este tipo de comportamento.

Bronfenbrenner (1996) levanta a hipótese que as crianças cuidadas em ambientes de grupo, desde a mais tenra idade, por grande parte do dia, tendem a manifestar comportamentos egocêntricos, de agressividade e anti-sociais, este tipo de comportamento é mais observado nos meninos. Embora não 
tenhamos informações precisas sobre as datas de ingresso destas crianças em instituições infantis, sabe-se que elas permanecem por um longo período no Prodecad, chegam pela manhã e ficam até o final da tarde. Por outro lado, há a hipótese de que a criança tem um comportamento mais egocêntrico no âmbito da casa, quando começa a freqüentar ambientes escolares tendem a modificar esta atitude, aprendendo a compartilhar, conviver em grupo, socializando-se.

Copetti e Krebs (2004) relatam que este comportamento exerce influência negativa sob os processos proximais, fomentando uma demanda negativa que desencorajam atitudes de interação de outras crianças. Esta manifestação disruptiva também foi encontrada no ambiente residencial da criança, sete casos foram relatados pelos pais, dois deles advindos de crianças que não manifestaram tal comportamento em aula. Durante as aulas estas crianças, por mais de uma vez, apresentaram comportamento de disposições disruptivas do pólo passivo, passando grande parte do tempo, sozinhas. Copetti (2001) explicita que apresentar comportamento disruptivo culmina em dificuldade em empenharse em processos que exigem padrões progressivamente mais complexos.

As disposições desenvolvimentalmente geradoras, que segundo Krebs (2003) são capazes de desencadear processos proximais, ocorreram na aula em atitudes de auxílio entre as crianças, empenho nas atividades e momentos de criatividade; nas residências estas ações também foram identificadas, com atitudes de criatividade das crianças e o engajamento ao interagir com o brinquedo.

No questionário para os pais, foram identificadas cinco manifestações de criatividade das crianças com o brinquedo, nos diários de campo foram constatadas três crianças que criaram algo diferente. Portanto, no âmbito da casa esta atitude apresentou uma freqüência maior, talvez pela ampla exploração realizada em aula.

A habilidade de uma criança em construir com maior facilidade o brinquedo também estimulou a formação de relações, pois a criança que terminava seu brinquedo, ajudava o outro. Este tipo de habilidade é considerado por Bronfenbrenner (1996) como um recurso do pólo positivo, sendo identificadas como competências da pessoa. (COPETTI, 2003; KREBS, 2003).

Quanto às demandas, ações que tem o poder de convidar ou desencorajar reações de outras pessoas, fomentando ou rompendo com processos de desenvolvimento (KREBS, 2003), puderam ser percebidas em diversos momentos, como por exemplo, em atitudes de manifestações agressivas, abstenção das 
atividades, dificuldade em dividir materiais, culminando em demandas negativas.

Demandas positivas foram identificadas em atitudes de auxílio, criatividade e também na formação de relações interpessoais. Uma criança, por exemplo, fomentou o estabelecimento de seis relações interpessoais, este comportamento demanda atitudes positivas de outras crianças. Bronfenbrenner (1996) analisa este fenômeno como a capacidade da criança ampliar seu mundo fenomenológico, participando efetivamente do ambiente a ponto de modificá-lo, aumentando sua estrutura e conteúdo.

Um fato importante observado foi o de que as crianças relacionaram-se menos nos momentos de atividades livres, foi possível identificar isto nas filmagens, pois na aula de construção da bola maluca houve treze relações, sendo sete de observação e seis de participação conjunta, no momento livre de exploração, não foi estabelecida nenhuma relação. $\mathrm{Na}$ aula de construção livre houve apenas cinco relações, quatro de participação conjunta e uma de observação. Com a análise do diário de campo da aula de construção da garrafa colorida, foram identificadas diversas relações de participação conjunta entre as crianças, pois à medida que terminavam a construção, auxiliavam aquelas que ainda estavam fazendo o brinquedo.

As aulas de atividades apresentaram algumas dificuldades no seu desenvolvimento, pois as crianças ficavam muito eufóricas com o brinquedo e não prestavam atenção às informações sobre algumas atividades que poderiam ser realizadas, após o período inicial em que havia a exploração individual do brinquedo construído. Este comportamento do grupo nos faz refletir quanto à idade em que se encontram, entre 4 e 5 anos, esta fase, de acordo com Piaget (1978), corresponde à transição do comportamento direcionado para o comportamento socializado, caracterizando-se pelo egocentrismo até os cinco anos aproximadamente, depois ampliam a participação social e apresentam interesse nos relacionamentos interpessoais.

Outro ponto relevante postulado na teoria de Bronfenbrenner (1996), relata que à medida que a criança se desenvolve, torna-se capaz de executar mais de uma atividade molar ao mesmo tempo. Considerando que a interação com o brinquedo apresentou-se como uma atividade molar, as crianças ainda não conseguiam se relacionar umas com as outras e simultaneamente com a professora, a relação interpessoal, elemento do microssistema, executada em uma atividade molar exige elevada complexidade que emerge do modo como a criança lida com o ambiente, alterando-o de acordo com as suas necessidades. 
A TEDH explicita que as atividades molares apresentadas por terceiros à criança, "constituem a fonte principal de efeitos diretos do meio ambiente imediato sobre o crescimento psicológico" (BRONFENBRENNER, 1996, p. 39), concluindo que o desenvolvimento da criança reflete a complexidade das atividades molares em integração com as pessoas à sua volta. A capacidade de desenvolver mais de uma atividade molar ao mesmo tempo, tem suas raízes, segundo Bronfenbrenner (1996), no contato com os pais, no qual a criança adquire ou aperfeiçoa este tipo de habilidade, especialmente com a mãe, que a criança vê realizando mais de uma atividade ao mesmo tempo enquanto cuidam dos filhos.

Esta importante observação de Bronfenbrenner nos remete aos escritos de Winnicott (1975), estes revelam que o brincar, tipo de atividade molar realizada pela criança, surge entre o espaço potencial da mãe e do bebê. A criança começa a brincar criativamente quando percebe que não é mais parte da mãe, mas sim um ser à parte da mãe, assim pela confiança gerada pelo amor da mãe, a criança passa da dependência para a autonomia, abrindo um espaço potencial preenchido pela brincadeira.

Brincar, para Piaget (1978), é um importante meio de assimilação e de aprendizado para a criança, além de demonstrar regras e valores familiares, e culturais, ao mesmo tempo em que Winnicott (1982), enfatiza que promover tempo e espaço para que a brincadeira aconteça, é de suma importância, pois brincando a criança relaciona-se emocionalmente e desenvolve contatos sociais.

\section{CONSIDERAÇÕES FINAIS}

Compreendendo o Prodecad como um microssistema, as aulas de construção de brinquedos representaram como um contexto de desenvolvimento, proporcionando tempo e espaço para as crianças atuarem de forma criativa. Nestas aulas, as atividades desenvolvidas foram consideradas molares.

Os encontros com as crianças para a construção do brinquedo foram, de acordo com relatos da professora da sala, esperados ansiosamente por elas. Construir o brinquedo era algo prazeroso para as crianças, nos momentos de aula elas apresentavam-se concentradas e determinadas.

$\mathrm{O}$ ato de explorar os brinquedos certamente foi molar, as crianças não conseguiam se interessar nas propostas de atividades sugeridas pela professora, pois queriam "apenas" brincar, ao seu modo, por este motivo as relações de observação e de participação conjunta foram escassas durante este período. Mas, ao levar o brinquedo para a casa, as relações de participação conjunta aconteceram. Por outro lado, o ato 
de desenvolver atividades dirigidas com os brinquedos pôde ser considerado molecular, pois as crianças não se engajaram de forma contínua nas atividades propostas na aula.

As relações interpessoais que ocorreram foram fomentadas pelos atributos das crianças. Quanto às disposições, atitudes de engajamento, auxílio entre as crianças, criatividade e imitação, foram manifestações que ocorreram em grande número durante as aulas, estas foram as desenvolvimentalmente geradoras. Os recursos do pólo ativo também possibilitaram o relacionamento entre as crianças, como por exemplo, a habilidade em construir o brinquedo com mais facilidade. As demandas positivas de algumas crianças incitaram manifestações de outras.

No outro microssistema, a casa da criança, também foram manifestadas atitudes que possibilitaram a formação de relações interpessoais, mais precisamente, relações de participação conjunta. Os atributos da pessoa que instigam a formação dos processos proximais, aconteceram no âmbito da casa.

Alguns atributos da pessoa foram capazes de limitar, romper ou anular, a formação de relações interpessoais entre as crianças, como as disposições desenvolvimentalmente disruptivas do pólo ativo, compreendidas em atitudes de desentendimento, este tipo de atitude foi manifestado na casa da criança também; e do pólo passivo, como recusa de participação em atividades. Os recursos do pólo negativo, como deficiência física, resultado insuficiente no teste de coordenação e alterações na avaliação nutricional, foram identificados em alguns casos específicos. Estes dois tipos de atributos, demandam atitudes que desencorajaram a aproximação de outras crianças.

Neste estudo, não foi possível relacionar o fato da participação da família (pais ou responsáveis), em responder ao questionário com as manifestações comportamentais das crianças durante as aulas. As hipóteses de que os pais integrantes deste sistema ecológico influenciaram as atitudes das crianças em aulas permanece em aberto, pois neste estudo obtivemos apenas dois questionários respondidos, fato este que impossibilitou qualquer tipo de correlação.

Contudo, nos questionários percebeu-se que a maioria das crianças interagiu com os familiares por meio do brinquedo, apenas mostrando, brincando efetivamente ou até brigando com membros da família. Este tipo de interação corrobora a continuidade do processo, já que o ato de construir um brinquedo artesanal se contrapõe com os objetivos das interações que a criança tem com os brinquedos industrializados. 
Ao retomar os princípios da TEDH base deste estudo, encontramos em seus pressupostos que a ocorrência de mudanças em relação às concepções ou nas atividades da pessoa, transferindo-as para outros ambientes e a outros momentos, constitui indicativos de alterações nas relações interpessoais, podendo ter repercussões positivas para o desenvolvimento ulterior da criança. Refletindo acerca desta vertente, as aulas de construção de brinquedos foram capazes de promover alterações em outro ambiente, na casa da criança, contribuindo para a intensificação das interações interpessoais.

\section{REFERÊNCIAS}

BRONFENBRENNER, U. A ecologia do desenvolvimento humano: experimentos naturais e planejados. Porto Alegre: Artes Médicas, 1996.

COPETTI, F. Estudo exploratório dos atributos pessoais de tenistas. 2001.Tese (Doutorado) - Faculdade de Educação Física, Universidade Federal de Santa Maria, Santa Maria, 2001.

- Atributos pessoais de crianças que se engajam na prática esportiva: um olhar orientado pelo modelo bioecológico. In: KREBS, R. J. (Org.). Os processos desenvolvimentais na infância. Belém: GTR, 2003. v. 1

COPETTI, F.; KREBS, R. J. As propriedades da pessoa na perspective do paradigma ecológico. In:

KOLLER, S. H. (Org.). Ecologia do desenvolvimento humano: Pesquisa e intervenção no Brasil. São Paulo: Casa do Psicólogo, 2004. p. 67-89.

DE MARCO, M. C. Manifestações Emocionais em Atividades Motor as de crianças de 5 e 6 anos de idade da Educação Infantil. 2006. Dissertação (Mestrado) - Faculdade de Educação Física, Universidade Metodista de Piracicaba, Piracicaba. 2006.

FACHIN, O. Fundamentos de metodologia. 3. ed. São Paulo: Saraiva, 2001.

FARIA JUNIOR, A. G. Prática de ensino em Educação Física: estágio supervisionado. Rio de Janeiro: Guanabara, 1987.

KREBS, R. J. Novas tendências para o estudo do desenvolvimento humano. Prata da Casa, São Luís/MA, n. 11, p. 93-108, 2001 a.

. Desenvolvimento infantil: a ecologia dos processos desenvolvimentais. In: ROSSO, R. D. (Org.). Desenvolvimento infantil em contexto. Florianópolis: UDESC, p. 33-45,2001b.

- A criança e o esporte: reflexões sustentadas pela teoria dos sistemas ecológicos. In:

KREBS, R. J. (Org). Os processos desenvolvimentais na infância. Belém: GTR, v. 1, 2003.

- Considerações organizacionais para o planejamento efetivo de uma aula. Santa Maria: Ed. da UFSM, 2004. 
- Os contextos sócios-culturais família e escola: uma reflexão sustentada por três teorias do desenvolvimento humano. Revista Multidisciplinar do Centro Universitário de São José. São José, v. 1, n. 1, p. 55-67, 2005.

PIAGET, J. A Formação do símbolo na criança: imitação, jogo e sonho, imagem e representação. Rio de Janeiro: Zahar, 1978.

VIGOTSKI, L. S. A formação social da mente. São Paulo: Martins Fontes, 2007.

WINNICOTT, D. W. O brincar e a realidade. Rio de Janeiro: Imago, 1975.

. A criança e o seu mundo. 6. ed. Rio de Janeiro: Guanabara Koogan, 1982. 


\section{Tatiane Goibertoni Sia}

\section{Faculdade de Educação Física- UNIMEP}

\section{Ademir De Marco}

Faculdade de Educação Física- UNICAMP

\section{Referência do artigo:}

\section{ABNT}

SIA, T. G., MARCO, A. Construindo brinquedos na educação infantil: uma experiência com a teoria ecológica do desenvolvimento humano. Conexões, v. 6, p. 331-343, 2008.

\section{APA}

Sia, T. G., \& Marco, A. (2008). Construindo brinquedos na educação infantil: uma experiência com a teoria ecológica do desenvolvimento humano. Conexões, 6, 331-343.

\section{VANCOUVER}

Sia TG, Marco A Construindo brinquedos na educação infantil: uma experiência com a teoria ecológica do desenvolvimento humano. Conexões, 2008; 6: 331-343. 